\title{
Effect of Distance between Double Glazing on the Performance of a Solar Thermal Collector Control
}

\author{
Nabila Ihaddadene, Razika Ihaddadene and Azzeddine Mahdi \\ Department of Mechanical Engineering, M'Sila University, M'Sila 28000, Algeria
}

Received: February 13, 2015 / Accepted: March 04, 2015 / Published: March 25, 2015.

\begin{abstract}
In this research paper, an attempt has been made to come across the effect of distance between double glazing on the efficiency of a solar thermal collector. Experiments were carried out on an active solar energy demonstration system (ET 200). Commercial glass pane of $3 \mathrm{~mm}$ thick having the same dimensions as that of the apparatus was placed above the collector at a distance of $2 \mathrm{~cm}, 4 \mathrm{~cm}$ and $6 \mathrm{~cm}$. Tests were done with and without the added glass. Experiments were performed for double glazing with two positions of the light meter. In one position, it was placed in the middle of the collector surface. While, in the other one, the light meter was placed in the middle of the added glass. To study the effect of double glazing on the performance of the solar collector ET 200, the correct position of the light meter was to place it exactly in the middle of the additional pane under the lamp. Double glazing does not enhance the performance of the solar collector because of the high resistance of the system glass air glass. The efficiency of double glazing solar collector decreases with the increasing the distance of the two separated glasses.
\end{abstract}

Key words: Solar energy, solar collector, double glazing, distance between double glazing.

\section{Introduction}

The quest to reduce environmental impacts of the conventional energy resources and more importantly meeting the growing energy demand of the global population had oriented researchers attention toward clean and renewable energy sources [1]. Solar energy is the most important source of renewable energy in the planet [2]. One of the simplest and most direct applications of this naturally and freely available energy is to convert solar radiation into heat. This conversion is accomplished using solar panels with the objective of heating water or air for domestic and industrial applications [3].

Most solar water heating systems used in buildings have two main parts: a solar collector and a storage tank. Solar collectors are the key component of solar heating systems. They amass the sun's energy, transform its radiation into heat, and then transfer that

Corresponding author: Nabila Ihaddadene, lecturer, Ph.D., research fields: heat transfer, and renewable energy. E-mail: MAZ1dz@gmail.com. heat to a fluid (usually water or air). Solar water heating systems can be either active (use of pumps to move water between the collector and the storage tank) or passive (water circulates naturally as it is heated between the collector and the storage tank). The most common are active systems.

The solar water heating technology has considerably improved over the past century. Nowadays, many models of solar collectors are functional. Solar collector designs are classified in three general types; flat plate collectors, evacuated tube collectors and concentrating collectors. There is an increasing demand for the solar collectors, especially the flat plate collectors.

Several investigations have been devoted to flat plate solar collectors (with water or air) and especially with the aim of improving their performance [3-6]. The glass is quite interesting as a cover for solar devices since it absorbs most of the infrared radiation re-emitted by the absorber resulting in an improvement of the thermal efficiency of the solar collector. 
The aim of the present study was to investigate the effect of the distance between double glazing on the performance of a solar water heating system using the radiation of a halogen lamp to simulate the sun light.

The paper is organized as follows: Section 2 explains the experimental set up; Section 3 deals with the thermal analysis of the experimental device; Section 4 presents the experimental procedure; Section 5 presents experimental results and discussions; and Section 6 gives conclusions.

\section{Experimental Apparatus}

In this investigation, experiments were conducted on a fully functional demonstration model (ET 200) of a system for heating domestic water. This demonstrating model uses light radiation energy of a halogen lamp to simulate the sun energy as illustrated in Fig. 1.

The solar system for heating domestic water consists of (1) water storage tank, (2) a flat plate solar collector, (3) a high-power lamp and (4) a control and command cabinet.

Solar collector is a planar collector with a single glazing pivoting around an axis; it allows an inclination angle from $0^{\circ}$ to $60^{\circ}$. The absorber, which is the central element of the collector, consists of three bands of 320 $\times 120 \mathrm{~mm}^{2}$ each one.

It is traversed by series of tubes, which absorb the solar radiations and transfer heat absorbed to the tank water via the circulation of water exchanger fluid. Temperature measurements are performed by sensors

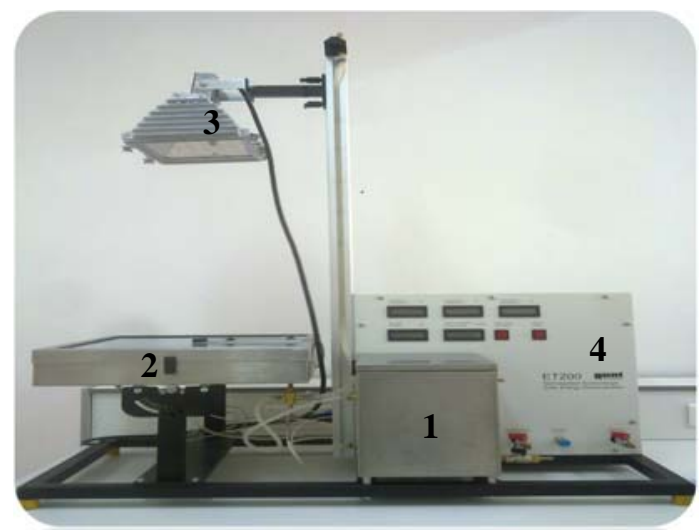

Fig. 1 Experimental device [7].
PT 100 placed at the inlet $T_{1}$, at the outlet $T_{2}$ of the absorber and in the storage tank $T_{3}$.

A pump for circulating water is used by the system. The flow control is provided by a valve for regulating the volume flow located on the control and command cabinet.

Halogen lamp high power (max 1,000 W) simulating natural sunlight is used in our study. Thus, the naturally incident solar radiation is replaced by the halogen lamp.

Illuminance measurement is carried out with a heliometer.

The measures of water flow rate, temperature and illuminance are shown on the digital displays of the control and command cabinet (Fig. 1).

\section{Gouverning Equations}

In a steady state, the energy balance of the collector area is given by the following equation [8]:

$$
E=E_{u}+P
$$

where, $E$ : incident solar flux received by the glass surface of the solar collector (W); $E_{u}$ : useful flux, i.e., incident solar flux received by the fluid (water) (W); $P$ : fluxes lost by convection and conduction towards the back of the collector and by convection, conduction and radiation forwards of the collector.

\subsection{Incident Solar Flux}

The power transmitted to the flat plate collector surface is captured directly by the light meter placed exactly in the middle of the collector surface under the lamp to obtain correct measured results. Its value (per square meter) is read on the control and command cabinet. This value must be multiplied by a correction factor of 2.95 to get the real value as mentioned by the user manual of the apparatus [9]. The incident solar flux by the glass surface $\left(\mathrm{W} / \mathrm{m}^{2}\right)$ of the solar collector is expressed by:

$$
E=G \times S
$$

where, $G$ : illuminance, i.e., incident solar flux by glass 
surface $\left(\mathrm{W} / \mathrm{m}^{2}\right)$ and $S$ : exposed area to radiation $\left(\mathrm{m}^{2}\right)$.

\subsection{Useful Flux}

The useful flux recovered by water is given by the following equation:

$$
E_{u}=\dot{m} \times C_{p} \times\left(T_{2}-T_{1}\right)
$$

where, $m$ : water mass flow rate $(\mathrm{kg} / \mathrm{s})$, which is related to the volumetric flow rate by the following relation:

$$
\dot{m}=\rho \times Q_{v}
$$

where, $Q_{v}$ : volumetric flow rate $\left(\mathrm{m}^{3} / \mathrm{h}\right) ; \rho$ : water density $\left(\mathrm{kg} / \mathrm{m}^{3}\right) ; C_{p}$ : Water specific heat; $T_{2}$ : water outlet temperature of the absorber; $T_{1}$ : water inlet temperature of the absorber.

\subsection{Instantaneous Solar Collector Efficiency}

The instantaneous efficiency of a solar collector is defined as the ratio between the irradiance available from the lamp and the useful power drawn off via the water heat transfer medium $[8,10]$ :

$$
\eta=\frac{E_{u}}{E}
$$

\section{Effect of the Distance between Double Glazing}

To highlight the effect of the distance between double glazing on the ET 200 solar collector performance, all the experiments done were carried out with water flow rate of $5.8 \mathrm{l} / \mathrm{h}$, taking the whole surface of the collector (Stotal $=0.13838 \mathrm{~m}^{2}$ ) maintained at an horizontal position.

Commercial glass pane of $3 \mathrm{~mm}$ thick having the same dimensions as that of the apparatus was placed above the collector at a distance of $2 \mathrm{~cm}, 4 \mathrm{~cm}$ and $6 \mathrm{~cm}$. To see the effect of double glazing, tests were done with and without the added glass.

In order to determine the correct location of the light meter, experiments were performed for double glazing with two positions of the light sensor. In one position, it was placed in the middle of the collector surface. While, in the other one, the light meter was placed in the middle of the added glass.

Each test lasted $150 \mathrm{~min}$, and the absorber water inlet temperature $T_{1}$, the absorber water outlet temperature $T_{2}$ and the tank temperature $T_{3}$ were recorded every five (05) minutes. All tests were performed in laboratory at an ambient temperature of $23 \pm 1^{\circ} \mathrm{C}$.

\section{Experimental Results}

The first treatment of the obtained results permitted us to note that temperatures $T_{1}, T_{2}$ and $T_{3}$ were independent of the light meter location. In contrast, illuminance $(G)$ depended of the light meter location. The second treatment of the temperature results led us to plot the evolution of the temperatures $T_{1}, T_{2}$ and $T_{3}$ over time. Graphs showing the evolution of temperatures $T_{1}, T_{2}$ and $T_{3}$ versus time for all experiments performed have the same appearance. Fig. 2 shows an illustrative example for a distance of $2 \mathrm{~cm}$ between double glazing. As illustrated in Fig. 2, all temperatures $T_{1}, T_{2}$ and $T_{3}$ increase with time. Temperature $T_{2}$ is always greater than the other temperatures ( $T_{1}$ and $T_{3}$ ); it presents water temperature at the outlet of the absorber. Its value is higher due to the heat water absorption occurred in the absorber. Temperature $T_{1}$ has the lowest value after water passage in the tank where it yields a quantity of heat to water tank, as a result temperature $T_{3}$ increases.

The time interval when the temperature differs, as a consequence, the efficiency of the collector, are time independent is called steady state phase.

The effect of the distance between double glazing on the collector efficiency was studied during the steady state phase i.e., beyond $30 \mathrm{~min}[7,9]$. The result found is shown in Fig. 3 for different locations of the light meter.

As seen in Fig. 3, the effect of double glazing depends on the location of the light meter; double glazing enhances the performance of the solar collector 


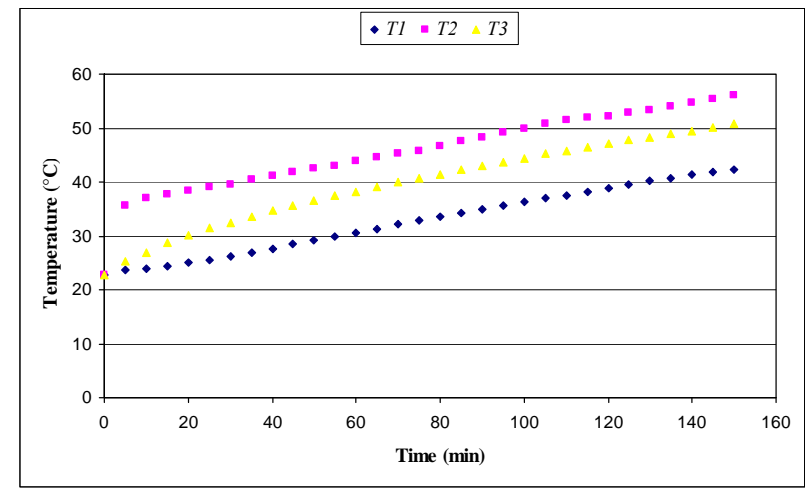

Fig. 2 Temperatures $T_{1}, T_{2}$, and $T_{3}$ evolution over time for a distance of $2 \mathrm{~cm}$ between double glazing.

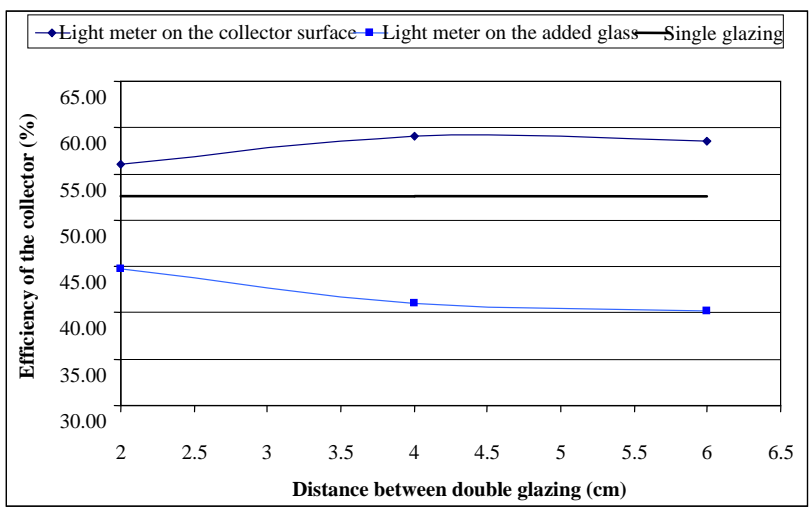

Fig. 3 Effect of the distance between double glazing on the performance of the thermal solar collector.

when the light meter is placed on the collector surface. Conversely, it decreases the efficiency of the collector when the light meter is on the added glass. In fact, this finding is due to the incident solar flux received by the glass collector surface (light meter placed on the collector surface) or by the added glass (light meter on the additional pane). In addition, the energy reaching the lower glass (collector surface) in the presence of the added glass is smaller than that received by this former.

The above collector efficiency can be written as:

$$
\eta=\frac{\dot{m} \times C p \times\left(T_{2}-T_{1}\right)}{G \times A_{c}}
$$

Temperature difference, glass surface collector, mass water flow rate and water specific heat were constants for each experiment. While Illuminance $G$ varied with the position of the light sensor. According to Eq. (6), the efficiency of the solar collector is inversely proportional to the incident solar flux which explains the result found.

In order to determine if double glazing enhances or not the efficiency of the solar collector, we have plotted the evolution of the tank temperature $T_{3}$ versus time for single glazing and different distances between double glazing (Fig. 4). As mentioned previously, tank temperature was independent of the light meter location.

As seen in Fig. 4, double glazing decreases the storage tank temperature. This result was found also for the temperature difference between the collector feed and return $\left(T_{2}-T_{1}\right)$, as a consequence of the energy received by the glass collector surface.

In addition, the objective of this solar water heating system is to heat water i.e., raise water tank temperature $T_{3}$ by absorbing the maximum heat at the flat plate collector (maximizing temperature difference $\left.\left(T_{2}-T_{1}\right)\right)$. Thus, it seems that double glazing in our case decreases the efficiency of the solar collector.

So, to study the effect of double glazing on the performance of the solar collector ET 200, the light meter should be placed exactly in the middle of the additional pane under the lamp to obtain correct results.

The glass added is placed on a dial wood having the same dimensions as the surface of the collector. Thus, the air is trapped between the two panes (glass surface collector and the added glass).

The thermal resistance of the system glass-air-glass (Fig. 5) increases with the distance separating the two glasses, since air is a poor heat conductor (thermal conductivity of air $\lambda=0.026 \mathrm{~W} \cdot \mathrm{m}^{-1} \circ \cdot \mathrm{C}^{-1}$ ).

Therefore, double glazing does not enhance the performance of the solar collector because of the high resistance of the system glass air glass. For example, if the distance between the glass surface collector and the added glass equals to $2 \mathrm{~cm}$, the efficiency of the ET 200 solar collector decreases with $15 \%$. A reduction of $23.67 \%$ was recorded for a distance of $6 \mathrm{~cm}$ between the two glasses. 


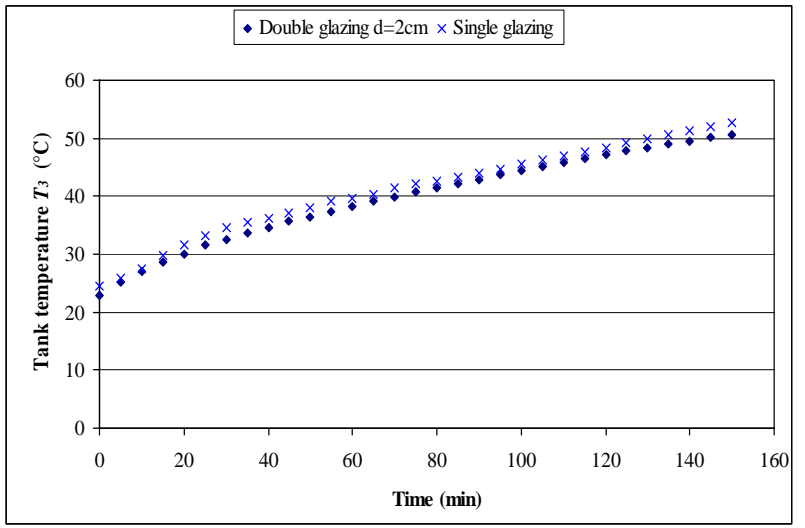

(a) $2 \mathrm{~cm}$ distance between the added glass and the collector surface.

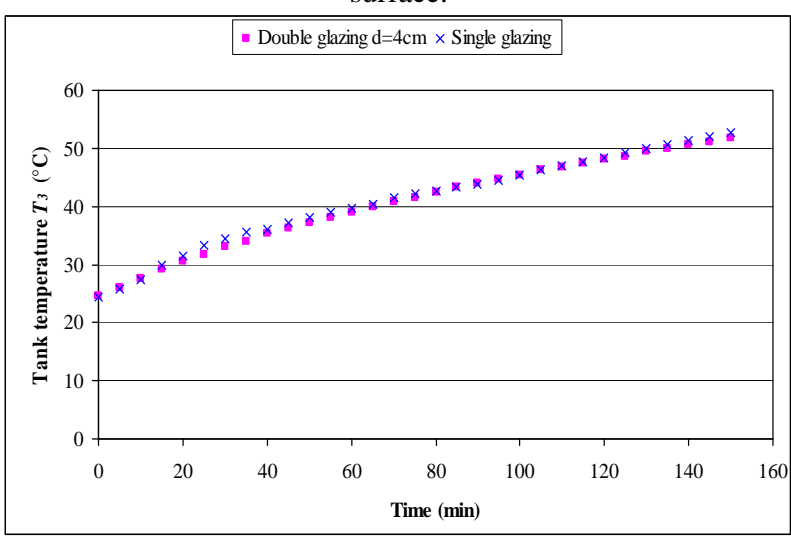

(b) $4 \mathrm{~cm}$ distance between the added glass and the collector surface.

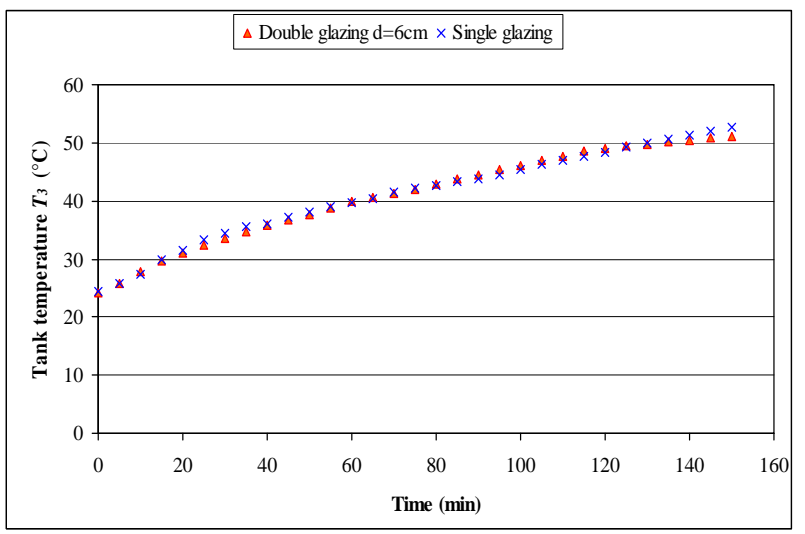

(c) $6 \mathrm{~cm}$ distance between the added glass and the collector surface.

Fig. 4 Tank temperature $T_{3}$ evolution over time for single glazing and different distances between double glazing.

When the distance between the two glasses equals to zero "glasses overlapping" the effect studied in this case is the glass thickness effect. So, the thermal resistance will be reduced to the sum of the resistances of the two glasses and the performance of the thermal collector with double glazing will be improved.

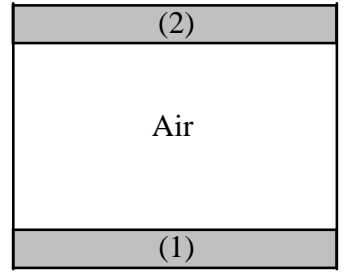

Fig. 5 Glass-air-glass system: (1) glass surface collector and (2) added glass.

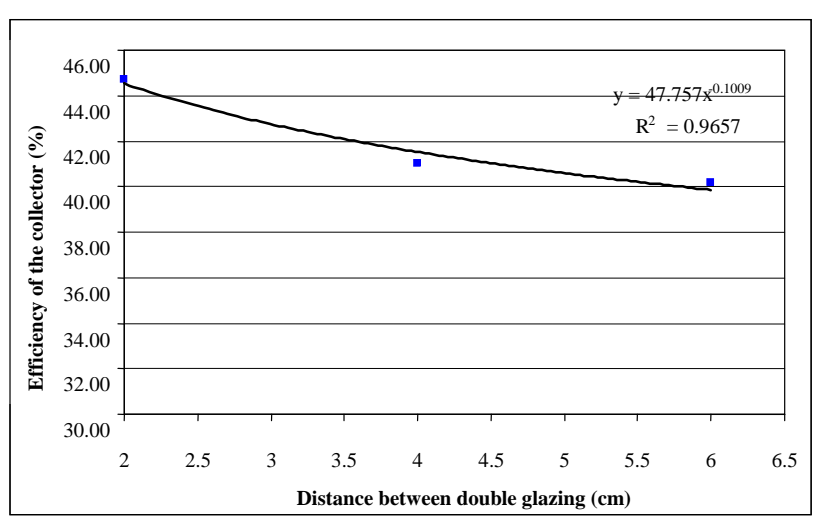

Fig. 6 Effect of varying glass pane distance on the efficiency of double glazing solar collector.

The influence of the distance between double glazing on the efficiency of the solar collector studied is shown in Fig. 6. The efficiency of double glazing solar collector decreases with the increasing the distance of the two separated glasses.

From these results, the following mathematical relationship that connects the efficiency of double glazing thermal collector to the distance between the two glasses (d) can be proposed as:

$$
\eta=47.76 \times d^{-0.10}
$$

where, $\eta$ : double glazing thermal collector efficiency in \%; $d$ : distance between the two panes in $\mathrm{cm}$.

This correlation has a determination coefficient $\left(R^{2}\right)$ of 0.9657 .

\section{Conclusions}

This study addressing the effect of distance between double glazing on the performance of ET 200 solar plane collector led us to remember the following points:

- In order to conduct this study, the light meter 
should be positioned on the additional pane not on the collector surface;

- The effect of the double glazing depends on the characteristics of the glass added, in this case, a normal glass of $3 \mathrm{~mm}$ thick was added, double glazing thus obtained does not improve the performance of the solar collector studied;

- The efficiency of double glazing solar collector decreases with increasing the distance separating the two glasses according to the following equation: $\eta=$ $47.76 \times d^{0.10}$ showing a high correlation coefficient $\left(R^{2}=0.9657\right)$.

\section{References}

[1] Adaramola, M. S. 2012. "Estimating Global Solar Radiation Using Common Meteorological Data in Akure Nigeria." Renewable Energy 47: 38-44.

[2] Almorox, J., Bocco, M., and Willington, E. 2013. "Estimation of Daily Global Solar Radiation from Measured Temperatures at Cãnada de Luque, Cõrdoba, Argentina.” Renewable Energy 60: 382-7.

[3] Hazami, M., Kooli, S., Lazaar, M., Farhat, A., and Belghith, A. 2005. "Performance of a Solar Storage Collector.” Desalination 183: 167-72.
[4] Youcef-Ali, S. 2005. "Study and Optimization of the Thermal Performances of the Offset Rectangular Plate Fin Absorber Plates, with Various Glazing.” Renewable Energy 30: 271-80.

[5] Tang, R., Sun, Z., Li, Z., Yu, Y., Zhong, H., and Xia, C. 2008. "Experimental Investigation on Thermal Performance of Flat Plate Collectors at Night.” Energy Conversion and Management 49: 2642-6.

[6] Aoues, K., Moummi, N., Zellouf, M., Moummi, A., Labed, A., Achouri, E., and Benchabane, A. 2009. “Amélioration des performances thermiques d'un capteur solaire plan à air: étude expérimentale dans la région de Biskra.” Revue des Energies Renouvelables 12: 237-48.

[7] Ihaddadene, R., Ihaddadene, N., Bey, M., and Hamidibacha, F. Z. 2014. "The Effects of Volumetric Flow Rate and Inclination Angle on the Performance of a Solar Thermal Collector." Energy Conversion and Management 78: 931-7.

[8] Slama, R. B. 2010. "Experimentation of a Plane Solar Integrated Collector Storage Water Heater.” In Proceedings of International Renewable Energy Congress, 395-403.

[9] Instrumentation Manual. 2003. ET 200 Solar Energy Demonstration. G.U.N.T.

[10] Mokhtari, F., and Semmar, D. 1999. "Expérimental d'un Capteur Solaire à Air.” Revue des Energies Renouvelables: 243-246. 